В. П. Саганов, Б. Б. Дондоков, Ж. Б. Очиров, А. А. Ооржак. Кровотечение из варикозно расширенных вен тонкой кишки. Разбор клинического случая

Научная статья

УДК 0616.34-005.1

DOI: 10.18101/2306-1995-2021-1-25-30

\title{
КРОВОТЕЧЕНИЕ ИЗ ВАРИКОЗНО РАСШИРЕННЫХ ВЕН ТОНКОЙ КИШКИ. РАЗБОР КЛИНИЧЕСКОГО СЛУЧАЯ
}

Саганов В. П., Дондоков Б. Б., Очиров Ж. Б., Ооржак А. А.

\section{(C) Саганов Владислав Павлович}

доктор медицинских наук, доцент, главный внештатный хирург МЗ РБ, главный специалист по развитию хирургической помощи vlad-saganov@yandex.ru

\section{(C) Дондоков Батор Бальжинимаевич}

заведующий хирургическим отделением bsmp@mail.ru

\section{(C) Очиров Жаргал Баирович}

врач-хирург

bsmp@mail.ru

\section{(C) Ооржак Аяс Анатольевич}

врач-хирург

bsmp@mail.ru

Республиканская клиническая больница скорой медицинской помощи имени В. В. Ангапова Россия, 670001, г. Улан-Удэ, проспект Строителей, 1

\section{Для цитирования}

Кровотечение из варикозно расширенных вен тонкой кишки. Разбор клинического случая / В. П. Саганов, Б. Б. Дондоков, Ж. Б. Очиров, А. А. Ооржак // Вестник Бурятского государственного университета. Медицина и фармация. 2021. № 1. С. 25-30.

Аннотация. В статье представлен клинический разбор рецидивирующего кровотечения из варикозно расширенных вен тонкой кишки. Работа дополнена современным обзором литературы по проблеме варикозных кровотечений из эктопических вариксов желудочно-кишечного тракта. Патология встречается очень редко, и при поиске источника кровотечения из желудочно-кишечного тракта врачи сталкиваются со множеством проблем в верификации точного диагноза и, соответственно, успешного лечения этого сложного заболевания. Анатомические особенности варикозно расширенных вен тонкой кишки затрудняют диагностику, что нередко приводит к инвазивным, а порой к хирургическим вмешательствам у данной категории пациентов. Если источник кровотечения не установлен вовремя, то замедление в лечении может привести к фатальным последствиям. Внимание к этой проблеме связано с большими сложностями в диагностике заболевания, ограниченным набором лечебных манипуляций и высокой летальностью при возникновении грозных осложнений.

Ключевые слова: синдром портальной гипертензии, варикозное расширение вен пищевода, портальное кровотечение, эктопические вариксы 


\section{Введение}

Варикозное расширение вен (ВРВ) желудочно-кишечного тракта (ЖКТ) одно из наиболее грозных осложнений синдрома портальной гипертензии. Указанное состояние может сформироваться при многих патологических механизмах, и в 90\% случаев к этому приводит цирроз печени $[5,11,12]$.

Лечение портальной гипертензии нацелено на уменьшение давления в системе воротной вены. Хирургическое лечение более действенно и приводит к уменьшению притока крови по воротной вене, которое получаем с помощью удаления селезенки, формируется искусственный портокавальный анастомоз методом соединения начала селезеночной вены в нижнюю полую вену $[1,3,8]$.

У больных циррозом печени коллатеральное кровообращение весьма усиленно, в 70\% случаев обнаруживается варикозное расширение вен пищевода, которое завершается острым кровотечением [7]. Таким же образом осуществляется сброс крови в желудок, что составляет от 10 до 20\% обильных кровотечений при портальной гипертензии [9] в вены прямой кишки, толстой кишки, передней брюшной стенки. Тем не менее до сих пор остаются вопросы: осуществляется ли сброс крови в участок тонкой кишки, какие происходят изменения в данной зоне и имется ли какая-нибудь связь с происходящими трансформациями в области пищевода и в остальных зонах желудочно-кишечного тракта $[2,4,6]$.

Портальная гипертензия - очень опасное осложнение цирроза печени, приводящее к кровотечению из области желудочно-кишечного тракта, в основном из варикозно измененных вен области пищевода, что является основной причиной летальности пациентов $[5,10]$.

Эктопическиие вариксы - это любые варикозно измененные венозные портокавальные коллатерали различной области желудочно-кишечного тракта, которые возникают из-за имеющегося синдрома портальной гипертензии и с высокой возможностью кровотечения в различных областях (яичники, желчный пузырь, брюшина, передняя брюшная стенка и др.) [12, 14]. Однако выявление желудочных вариксов не оказывает влияния на прогноз и выживаемость больных. Тем не менее кровотечение из вариксов весьма опасно, даже при низкой действенности эндоскопических манипуляций. В этой связи в современных лечебнодиагностических рекомендациях верификация кровотечений из пищеводных и желудочных вариксов является наиболее предпочтительной $[13,16]$.

В настоящее время по вопросу эктопических вариксов глубоких рандомизированных исследований не проводилось, данные имеют собирательный характер и состоят из описания редких эпизодов, наблюдений и коротких обзоров. Трудность верификации данного диагноза объясняется вариабельностью клиники и невозможностью топической и визуальной диагностики [15].

\section{Разбор клинического случая}

Больной Г., 58 лет, находился на стационарном лечении в РК БСМП с 03.03 по 18.03.2020 г.

Пациент поступил через 7 суток от начала заболевания. При поступлении жаловался на одышку, сердцебиение, общую слабость, головокружение, слабость в ногах. В приемно-диагностическом отделении БСМП осмотрен дежурным терапевтом и госпитализирован в отделение терапии.

Диагноз при поступлении: хроническая смешанная анемия тяжелой степени.

Сопутствующий: хронический субатрофический колит. 
В. П. Саганов, Б. Б. Дондоков, Ж. Б. Очиров, А. А. Ооржак. Кровотечение из варикозно расширенных вен тонкой кишки. Разбор клинического случая

Из анамнеза известно: в сентябре 2019 г. получал стационарное лечение по поводу анемии, черного стула $(\mathrm{Hb}-64$ г/л) в отделении терапии БСМП, при выписке анемия компенсирована (при выписке $\mathrm{Hb} 75$ г/л, Er 2,82×1012/л). В декабре 2019 г. получал терапию в хирургическом отделении с подозрением на острую тонкокишечную непроходимость, которая купировалась консервативно. В январе 2020 г. выписан из терапевтического отделения БСМП с диагнозом: смешанная анемия $(\mathrm{Hb}-89$ г/л), после чего продолжил амбулаторную терапию. В конце февраля появились вышеуказанные жалобы, с 02.03.2020 г. резкое ухудшение и появление черного стула. 03.03.2020 г. госпитализирован в терапевтическое отделение БСМП. 04.03.2020 г. больной переведен в отделение реанимации и интенсивной терапии № 3 (ОРИТ № 3), консультирован хирургом, после чего был переведен в профильное реанимационное отделение для хирургических больных (ОРИТ № 2), с диагнозом: желудочно-кишечное кровотечение неуточненной этиологии. В условиях ОРИТ № 2 получал интенсивную терапию (ИВЛ, инфузионная с коррекцией анемии, КЩС, ВЭБ, дезинтоксикационная, гемотрансфузионная, антибактериальная, противоязвенная, симптоматическая, гемостатическая, профилактика пролежней, ТЭО).

07.03.2020 г. ухудшение общего состояния в виде гипотонии (90/60 мм рт. ст.), выраженной слабости, головокружения. На момент осмотра $\mathrm{Hb}-66$ г/л. Учитывая неэффективность консервативной терапии, показано оперативное лечение в объеме: лапаротомия, ревизия брюшной полости, остановка кровотечения. 07.03.2020 г. 20.15-21.35 выполнена операция: среднесрединная лапаротомия, перевязка варикозно расширенных вен тонкой кишки, дренирование брюшной полости.

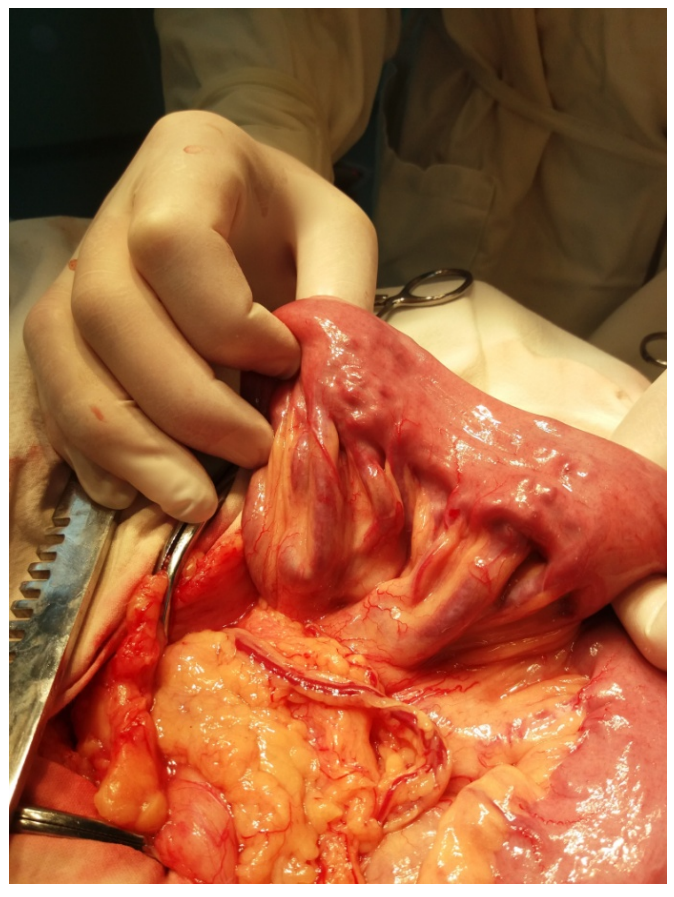

В ходе операции выявлено: во всех отделах имеется серозногеморрагический выпот до 400.0 мл. В просвете толстой кишки определяется кровь. Печень и селезенка умеренно увеличены в размерах, обычной окраски. При ревизии на 40.0 см от связки Трейца определяются варикозно расширенные вены тонкой кишки до $0,6-0,7$ мм в диаметре на протяжении 20-25 см (рис. 1).

Рис. 1. Варикозно расширенные вены тонкой кишки до $0,6-0,7$ мм 
Кроме того, определяются увеличенные вены по большой и малой кривизне желудка до 1.0 см (рис. 2). Варикозно расширенные вены тонкой кишки распространяются на стенку тонкой кишки.

Ситуация расценена следующим образом: источник кровотечения локализуется в данном участке тонкой кишки, в связи с чем произведена перевязка варикозно расширенных вен в этом сегменте, гемостаз.

Послеоперационный диагноз: варикозно расширенные вены тонкой кишки, осложненные кровотечением.

В послеоперационном периоде проводилось лечение в условиях ОРИТ № 2. После стабилизации состояния 10.03.2020 г. переведен в хирургическое отделение. В отделении продолжено лечение: гемостатическая, симптоматическая, антибактериальная терапия, обезболивание, прописаны препараты железа.

После проведенной терапии у больного наблюдалось положительная динамика, признаков продолжающегося кровотечения нет. Выписан 18.03.2020 г. в удовлетворительном состоянии на долечивание у участкового терапевта, хирурга.

Рис. 2. Варикозно расширенные вены по большой кривизне желудка

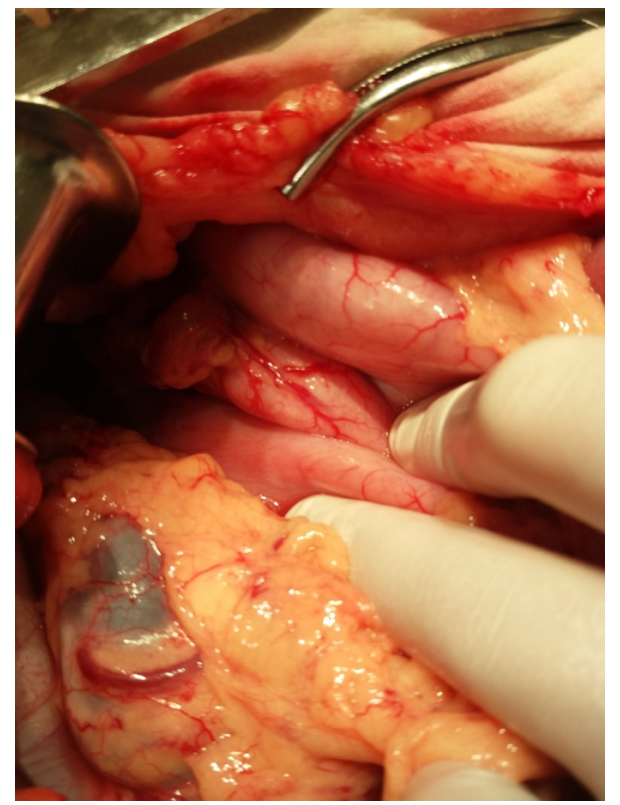

Проведенные обследования при выписке:

ОАК: гемоглобин - 98 г/л; лейкоциты - 2.6x109/л; СОЭ - 34 мм/ч. ОАМ: с/жел., проз., уд. вес - 1012, кисл., белок - нет, лейк. - един., эпит. пл. - 2-4 в п/зр. БАК: билирубин - 4,8 мкмоль/л; мочевина - 4,3 ммоль/л; сахар - 5,0 ммоль/л. ФГДС от 05.03.2020 г.: НК1 ст. Эрозивный рефлюкс - эзофагит. Анемизация слизистой ЖКТ. Косвенные признаки ДЖВП. ФКС от 06.03 .2020 г. Осмотр затруднен. Кал + кровь. Обзорная рентгенография грудной клетки от 03.03.2020 г., 04.03.2020 г. Закл.: без видимой патологии. Доза - 0.52 мзв.

Консультация гематолога от 05.03.2020 г. Закл.: Смешанная мегалобластная В12 и фолиевая дефицитная анемия тяжелой степени.

Основной диагноз: варикозно расширенные вены тонкого кишечника.

Осложнение: кровотечение из варикозно расширенных вен тонкой кишки. Смешанная анемия (постгеморрагическая, мегалобластная В12 и фолиевая дефицитная) тяжелой степени.

Сопутствующий диагноз: хронический субатрофический колит, обострение. 
В. П. Саганов, Б. Б. Дондоков, Ж. Б. Очиров, А. А. Ооржак. Кровотечение из варикозно расширенных вен тонкой кишки. Разбор клинического случая

\section{Выводы}

Данный клинический случай является наглядным образцом трудной диагностической локализации эктопических вариксов, при наличии их вне зоны доступности фиброгастродуоденоскопии и фиброколоноскопии. В связи с этим в случае возникшего кровотечения из эктопических вариксов хирургическое лечение ввиду обширного поражения и большой контактной кровоточивости варикозно расширенных вен крайне ограниченно, что может определить возможный летальный исход.

Необходимо использование современных эндоскопических (видеокапсульная и баллонная энтероскопия) и рентгенологических (МСКТ- или МРТ-ангиография, портография) методов на практике, которые позволят решить вопрос в скринингрежиме до возникновения кровотечения.

\section{Лuтература}

1. Клинические рекомендации по лечению кровотечений из варикозно расширенных вен пищевода и желудка / РОХ. Воронеж, 2014. С. 3-12, 32. Текст: непосредственный.

2. Борисов А. Е., Кащенко В. А. Цирроз печени и портальная гипертензия. СанктПетербург: Синтез Бук, 2009. С. 6-10, 18-21, 66-76. Текст: непосредственный.

3. Th e management of portal hypertension: Rational basis, available treatment and future options / J. Bosch, A. Berzigotti, J. C. Garcia-Pagan [et al.] // J. Hepatol. 2008. Vol. 48. P. 68-93.

4. Федосьина Е. А., Маевская М. В., Галимова С. Ф. Лечение осложнений цирроза печени: методические рекомендации для врачей / под ред. В. Т. Ивашкина. 2009. Текст: непосредственный.

5. Болезни печени и желчевыводящих путей: руководство для врачей / под ред. В. Т. Ивашкина. Москва: М-Вести. 2002. 416 с. Текст: непосредственный.

6. Шерлок Ш., Дули Дж. Заболевания печени и желчных путей. Москва: ГЭОТАР; Медицина. 1999. 864 с. Текст: непосредственный.

7. Bornman P. C., Krige J. E., Terblanche J. Management of oesophageal varices // Lancet. 1994. 343:1079-84.

8. Gastric lesions in portal hypertension: Infl ammatory gastritis or congestive gastropathy / T. T. McCormack, J. Sims, I. Eyre-Brook [et al.] // Gut. 1985. 26:1226-32.

9. Радченко В. Г., Шабров А. В., Зиновьева Е. Н. Основы клинической гепатологии. Заболевания печени и билиарной системы. Санкт-Петербург: Диалект. Москва: БИНОМ. 2005. 864 с.: ил. Текст: непосредственный.

10. Viggiano T. R., Gostout C. J. Portal hypertensive intestinal vasculopathy: a review of the clinical, endoscopic, and histopathologic features // Am. J. Gastroenterol. 1992. 87:944-954.

11. Portal colopathy: prospective study of colonoscopy in patients with portal hypertension / R. A. Kozarek, V. A. Botoman, J. E. Bredfeldt [et al.] // Gastroenterology. 1991. 101:1192-1197.

12. Helmy A., Kahtani K. A., Fadda M. A. Updates in the pathogenesis diagnosis and management of ectopic varices // Hepatology International. 2008. № 2. P. 322-331.

13. Norton I. D., Andrews J. C., Kamath P. S. Management of ectopic varices // Hepatology. 1998. Vol. 28, № 4. P. 1154-1157.

14. Sarin S. K., Kumar C. K. N. Ectopic varices // Clinical Liver Disease. 2012. Vol. 1, № 5. P. $167-169$

15. Harold K. L., Schlinkert R. T. Upper gastrointestinal bleeding // ACS Surgery: Principles and Practice. WebMD Inc. 2004 (дата обращения: 15.01.2015).

16. Борисов А. Е., Кащенко В. А. Сравнительный анализ результатов лечения больных с острым варикозным пищеводно-желудочным кровотечением: роль эндоскопических технологий // Вестник хирургии им. И. И. Грекова. 2003. Т. 162, № 3. С. 88. Текст: непосредственный. 
17. Эндоскопическая склеротерапия и лигирование варикозно расширенных вен пищевода и кардии / А. Е. Борисов, В. А. Кащенко, Е. Л. Васюкова, Д. В. Распереза // Хирургия. 2002. № 8. С. 36. Текст: непосредственный.

Статья поступила в редакиию 09.01.2021; одобрена после рецензирования 25.01.2021; принята к публикации 09.04.2021.

\title{
BLEEDING FROM VARICOSITIES OF THE SMALL INTESTINE. AN ANALYSIS OF THE CLINICAL CASE
}

\author{
Saganov V. P., Dondokov B. B., Ochirov Zh. B., Oorzhak A. A. \\ Vladislav P. Saganov \\ Dr. Sci. (Medecine), A/Prof., \\ Chief Consultant Surgeon of the Ministry of Health of the Republic of Buryatia, \\ Chief Specialist in Development of Surgical Service \\ vlad-saganov@yandex.ru
}

\author{
Bator B. Dondokov \\ Head of Surgical Unit \\ bsmp@mail.ru
}

\section{Zhargal B. Ochirov \\ Surgeon \\ bsmp@mail.ru}

\author{
Ayas A. Oorzhak \\ Surgeon \\ bsmp@mail.ru
}

\section{Angapov Republican Clinical Emergency Care Hospital}

Stroiteley Prospect, Ulan-Ude 670001, Russia

Abstract. The article presents a clinical analysis of recurrent bleeding from varicosities of the small intestine. The work is supplemented by a review of new literature on the problem of varicose bleeding from ectopic varices of the gastrointestinal tract. This pathology is very rare, and when looking for a source of bleeding from the gastrointestinal tract, doctors are faced with many problems in diagnositics and successful treatment of this complex disease. Anatomy of varicosities of the small intestine complicates diagnostics, and this often leads to invasive or even surgical intervention. If the source of bleeding is not identified in time, then a delay in treatment can lead to fatal consequences. Attention to this problem is associated with great difficulties in diagnosis of this disease, limited number of therapeutic manipulations and high mortality in the cases of severe complications.

Keywords: portal hypertension syndrome, esophageal varices, portal bleeding, ectopic varices

\section{For citation}

Saganov V. P., Dondokov B. B., Ochirov Zh. B., Oorzhak A. A. Bleeding from Varicosities of the Small Intestine. An Analysis of the Clinical Case. Bulletin of Buryat State University. Medicine and Pharmacy. 2021; 1: 25-30 (In Russ.).

The article was submitted 09.01.2021; approved after reviewing 25.01.2021; accepted for publication 09.04.2021. 